\title{
Corpo e Moda pela Perspectiva do Contemporâneo
}

\author{
Body and fashion from the perspective of contemporary
}

\author{
Brandes, Aline Zandonadi; Graduanda; \\ Universidade Estadual de Londrina \\ aline_znd@yahoo.com
}

Souza, Patricia de Mello; Doutoranda;

Fac. de Arquitetura, Artes e Comunicação, UNESP

patmel@sercomtel.com.br

\begin{abstract}
RESUMO
O presente artigo discute a relação que se estabelece entre corpo e moda em meio às mudanças históricas e tecnológicas que transformaram a sociedade. A abordagem, sob a forma de levantamento histórico, permite o estudo das representações sociais e auxilia na identificação dos fatores que ocasionaram mudanças significativas no sistema e que reorientaram o comportamento, alterando valores e pensamentos. No contexto da contemporaneidade, a moda mostra-se ambígua, na medida em que atua como fator de diferenciação e ao mesmo tempo obedece a regras e padrões impostos.
\end{abstract}

Palavras Chave: Corpo; Moda; Contemporâneo.

\begin{abstract}
This article discusses the relationship established between the body and the concept of fashion among the historical and technological changes that have transformed the society. The approach is based on historical research. It allows the study of the social representations and it provides the means to identify the factors that caused major changes in the system, redirecting its behavior and modifying the values and thoughts of society. Nowadays, the fashion is ambiguous, since on one hand it acts as a differentiation factor and, on the other hand, it complies with the rules and standards self-imposed.
\end{abstract}

Keywords: Body; Fashion; Contemporary.

\section{O corpo - marca identitária}

Muitas são as possibilidades que se apresentam quando o assunto a ser abordado é o corpo, principalmente quando integrante do cenário contemporâneo. Torna-se fundamental abordar o contexto no qual se insere. Não é possível pensar o corpo hoje, na sua articulação com a subjetividade e a identidade, sem discutir a evolução do mundo, dos objetos e do mercado (VILLAÇA; GÓES, 1998). Atualmente, ele é objeto de discussão em diversas áreas, seja no aspecto da saúde, na estética, no meio artístico, ou como suporte para a moda, sempre atuante como um emissor de mensagens.

O corpo é o que nos torna presentes no mundo. Para Le Breton (1995), é caracterizado como um vetor da individualização, estabelecendo a fronteira da identidade pessoal. Através dele constrói-se a relação do indivíduo com o mundo, em meio ao contexto cultural e social em que se situa. A identidade cultural de cada pessoa está inscrita em seu corpo e manifesta-se nas informações que emanam dele e que produzem sentido continuamente. "Antes de qualquer coisa, a existência é corporal" (LE BRETON, 2006, p.7). Portanto, o corpo pode ser considerado como um índice das 
mudanças em curso na sociedade, uma vez que absorve e reflete as informações do ambiente no qual está inserido. Em seu desenvolvimento, é dependente do meio físico e dos contatos que estabelece. Padrões de comportamento, traços de uma cultura, diálogos sóciohistóricos, são aspectos que podem ser reconhecidos nos corpos, cuja realidade se funda no caráter comunicacional dos seres humanos (CASTILHO; MARTINS, 2005).

Embora o corpo seja considerado por diversos autores o primeiro veículo de comunicação e expressão do ser humano, concorda-se com Castilho e Martins (2005), que argumentam que estando nu, o indivíduo encontra-se desprovido de conotações, como se fosse um texto com um significado único. Villaça (2007) confirma que o corpo não fala senão quando cercado de artifícios, coberto de signos. Assim como os demais objetos da vida cotidiana, o vestuário atua como um conjunto de textos, repleto de signos, que projetados e articulados de modo a relacionar seus elementos, permite a compreensão da dinâmica que se instaura em determinada sociedade e em determinado período histórico. De acordo com Villaça e Góes (1998, p.37), “o homem nasce prematuramente com a pele muito frágil, necessitando de proteção artificial de natureza física e, mais ainda, simbólica, pois é simbolicamente que se processa sua passagem à identidade individual e comunitária". Nesse sentido, a roupa pode ser considerada uma segunda pele, que recobrindo a primeira, compõe com ela a aparência final do sujeito (CASTILHO; MARTINS, 2005). Quando um indivíduo opta por alguma cor, dentre diversas; ou escolhe determinado tecido ou adereço, ele está construindo a sua mensagem dentro do próprio contexto, expressando uma atitude, um comportamento, através da linguagem das roupas. Corpos e roupas existem de forma simbiótica. As roupas são energizadas por aqueles que as vestem, que por sua vez, são atualizados por elas (VILLAÇA; GÓES, 1998).

Para Avelar (2009), a roupa enfatiza a função de definição do ser social. Ela não se limita simplesmente a uma função de proteção, pudor ou adereço, mas impõe-se como elemento de diferenciação, tornando o vestir-se um ato de significar. Nesse contexto se estabelece a moda, que assim como o corpo, é uma forma de linguagem, um sistema constituído por signos, em busca de expressão e comunicação. A moda não trata apenas de tecidos, cores e formas, mas ela é também uma extensão do corpo. Por meio das escolhas realizadas pelo sujeito, ele concretiza, materializa sua subjetividade. Para Castilho (2004, p.9), "a moda pode ser considerada um ato de presença do próprio sujeito no mundo". Constitui-se como um dos extensores do próprio ser humano, filiando-o a determinados discursos sociais que expressam sua visão de mundo. De certa forma, todas as sociedades vestem o corpo, seja com pinturas, tatuagens, escarificações, perfumes ou roupas propriamente ditas, sempre com a intenção de construir seu discurso e significar algo. Ao inserir-se no contexto da cultura corporal, a moda é concebida como um sistema de significações por meio do qual o indivíduo cria valores e interage com o mundo e com o outro.

Pela perspectiva da psicologia, afirma Flügel (1966), a roupa pode ser tratada como extensão do corpo em relação aos desejos, gostos e hábitos. Ela interfere na maneira pela qual as relações com aquilo que está ao redor são estabelecidas, com o mundo no qual se faz parte. McLuhan (1964) compartilha tal questão ao afirmar que todo e qualquer artifício - a roupa, a casa, os meios de transporte, a televisão, a imprensa, dentre outros - utilizado pelo homem em suas tarefas e nas relações sociais constituem extensões de seu corpo. Dessa forma, a roupa integra a cultura corporal como extensão da pele, seja como mecanismo térmico, seja como um meio de diferenciação. A roupa compõe a imagem, concebe cada um como ser social e torna o corpo humano culturalmente visível. Constitui-se, portanto, uma "arquitetura têxtil que marca o papel do sujeito na sociedade" (CASTILHO; MARTINS, 2005, p.37). E como os demais discursos sociais, a moda concretiza desejos e necessidades de uma época. A cada época, a construção dos trajes e modos de vestir sofrem modificações, e o primeiro território onde isto se explicita é o próprio corpo, pois sobre ele fazem-se as marcas e os símbolos, expressam-se os gestos e mudam-se os adereços. O vestuário encontra-se necessariamente sintonizado às diversas formas que o corpo assume no decorrer da história humana.

Sendo o corpo o suporte das roupas e articulador de significantes, necessita revestir-se com as representações significativas de sua cultura e de seu contexto. No mundo contemporâneo, concordam Castilho e Martins (2005, p.37), o planejamento de um traje pode ser compreendido como "a arquitetura e a construção de um modelo de corpo que se insere na dinâmica, no desejo e na ordem 
social contemporânea". Um corpo com certo compromisso moral com as regras sociais, tendo que se ajustar a elas, e que ao mesmo tempo busca sua individualização a partir daquilo que veste (AVELAR, 2009). Não se trata mais de aceitá-lo como é, mas sim de corrigi-lo, transformá-lo e reconstruí-lo. E não se fala apenas de extensões, mas também de próteses internas e de interferências da biotecnologia. As modificações do corpo acabam provocando questionamentos sobre a identidade no mundo contemporâneo, em virtude dos diferentes modos em que se apresenta, das infinitas possibilidades de ser vestido, tecnologizado, desterritorializado e submetido a sacrifícios em função da aparência.

\section{A moda na construção da identidade}

O modo de vestir o corpo, a maneira pela qual cada cultura é incorporada a ele, determinando-o como único, é o elemento fundamental da diferenciação. Na eterna busca à identidade, a moda aparece como um dos primeiros fatores de distinção a partir do século XIX. Por mais que a moda seja uma dinâmica existente desde o século XV, é a partir de meados do século XIX que ela se articula diretamente à criação e à difusão das roupas, ao participar de um sistema de sociedade de classes advindo do capitalismo industrial e da sociedade burguesa (AVELAR, 2009). Até o século XVII, o sujeito e a roupa que o vestia formavam um conjunto coeso e coerente com as regras sociais de hierarquia, nacionalidade, gênero, e se permitia uma leitura dessas relações. Em sociedades pré-industriais, a forma de vestir indicava com muita precisão a posição do indivíduo na estrutura social (CRANE, 2006). Entretanto, o século XVIII trouxe uma novidade relacionada à questão do vestuário: a possibilidade de rompimento entre o ser e o parecer.

O desenvolvimento das cidades permitiu que se rompesse com a relação estabelecida entre o vestuário e a representação de pertencimento de uma determinada comunidade, profissão ou religião - vigente por muitos séculos - já que nas sociedades tradicionais, os papéis sociais eram relativamente fixos. O modo de vestir e a aparência indicavam imediatamente a classe social, a profissão e o status do indivíduo. O processo de industrialização causou a migração em massa dos trabalhadores das áreas rurais para os centros urbanos, ensejando o surgimento das metrópoles. Nessas grandes metrópoles em rápido crescimento, as pessoas vinham de diversos lugares, e praticamente ninguém conhecia ninguém. Cada um possuía sua própria história, e eram tantas pessoas e tão ocupadas, que a forma mais prática de identificação para conhecer uns aos outros, era a mais rápida e direta, isto é: através da maneira como se vestiam, pelos objetos simbólicos que exibiam, pelo modo e pelo tom com que falavam, por meio do próprio comportamento (SEVCENKO, 2001).

O livre trânsito de pessoas em um cenário no qual não havia um real conhecimento de quem eram aqueles indivíduos - diferentemente do que acontecia nos espaços restritos das vilas e aldeias, onde todos conheciam e reconheciam o seu pertencimento familiar, profissional, etário ou hierárquico - tornava necessária a decodificação de vários elementos visuais, entre eles, a roupa. As pessoas passaram a ter um convívio mais estreito e diversificado, tornando-se mais suscetíveis à avaliação das outras. As ruas tornaram-se lugares de exibição e competição, forçando as elites a criarem elementos de diferenciação antes restritos, de acordo com lugares e vestimentas, gerando uma reorganização nos espaços públicos e na própria dinâmica da moda. As pessoas, que nunca haviam estado tão próximas umas das outras por longos períodos de tempo, passaram a conviver em bondes e vagões de trens, 0 que as obrigavam a olhar umas para as outras (AVELAR, 2009).

No século XIX, as condições para que a aparência fosse cada vez mais dissociada do ser é consolidada, e de acordo com Wilson (1989), a aparência substituiu a realidade. Lipovetsky (1989) afirma que a moda tem ligação com o prazer de ver, mas também com o prazer de ser visto, de exibirse ao olhar do outro. A relação de cada indivíduo com o 'outro' também se dá através da roupa que o envolve, por isso, o corpo é um elemento de individualização e coletivização. Ao se vestir, portanto, o indivíduo pensa no modo que deseja ser visto pelo 'outro', procurando formas e meios muito diferenciados de se expressar, de articular sua aparência, criando e revelando determinados vínculos sociais. Há uma necessidade de ser visto, de tornar-se presente no mundo. A roupa comunica a identidade de quem a veste, e a imagem comunicada pode ser transmitida e compreendida de acordo com os padrões estabelecidos em cada sociedade. A imitação acaba se tornando uma prática coletiva 
em que o indivíduo busca identificação com o grupo - reconhecido como fator fundamental para a sua sobrevivência. Através da roupa, cada indivíduo escolhe o tipo de papel que quer desempenhar para adequar-se a determinado grupo. A moda permite a construção e exteriorização da subjetividade, que articulada com o consumo e a globalização, propõe identidades provisórias que vão mudando a cada momento (VILLAÇA, 2002). Segundo Castilho (2004), cada indivíduo, ao assumir esta ou aquela aparência, está constituindo parte de sua identidade.

\section{O corpo - objeto no mundo contemporâneo}

Como a identidade é fundamental para o indivíduo, vivencia-se uma intensa busca de significados durante a sua formação, com base nos múltiplos elementos culturais disponíveis no mundo contemporâneo. Na luta para constituir tal identidade, a imagem do corpo se estabelece como principal meio de construção. Assim, o corpo, um constante articulador de significantes, revestiu-se de representações significativas de sua cultura, de forma a interagir e representá-la em seus anseios, concepções, angústias e projeções (CASTILHO, 2006). Os movimentos do mundo contemporâneo agregaram ao corpo outras funções, que muitas vezes vão além de seu limite, na necessidade do ser humano em manifestar sua subjetividade. Por essa perspectiva, é inegável a valorização da imagem e da linguagem visual, como fonte imprescindível de comunicação. $O$ corpo, que na era industrial era manipulado como um instrumento da produção, sofreu modificações a partir do século XX, influenciado pela dinâmica socioeconômica e cultural que caracterizam esse período. Surge um mundo imerso em formas múltiplas, complexas, estratificadas, com fronteiras geográficas e econômicas praticamente diluídas (AVELAR, 2009).

As mudanças históricas e tecnológicas estabeleceram novos patamares e configurações de fatos, grupos, processos e circunstâncias, exigindo que o pensamento fosse reformulado em adequação aos novos termos, para poder interagir com o novo contexto. A predominância das máquinas, engenharias de fluxos e do compasso acelerado desse conjunto gerou uma mudança comportamental, afetando principalmente o quadro de valores da sociedade. Posterior à sociedade de produção, seguese a do consumo, na qual o indivíduo deixa de ser avaliado pelas suas qualidades pessoais ou diferenças que tornam única a sua personalidade, pois não havia mais tempo nem espaço para isso. As pessoas passam a ser aquilo que consomem, fundando uma cultura baseada na relação do parecer e não do ser, inseridas no contexto de um sistema centrado no mercado, e não nos valores humanos.

A percepção do corpo também é influenciada por essa sociedade da mercadoria, que é dominada pela existência de uma vasta gama de imagens, que propõem padrões de representação corporal. Nesse momento, o corpo deixa de funcionar como dado de identidade fixa e natural, lugar de delimitação e referência estável, tornando-se a expressão da identificação pela mutação, pela multiplicidade. Como um produto veiculado em diversas mídias, ele se torna objeto frequente da indústria do consumo, podendo ser manipulado e, consequentemente, produzido. A estrutura do capitalismo, baseada na força do trabalho disciplinado, aliada ao crescimento da indústria de serviços, modifica o estilo de vida da classe trabalhadora, enfatizando o consumo e o lazer (VILLAÇA; GÓES, 1998). A vida nas cidades maiores passa a ser dividida entre as horas do trabalho, destinadas ao ganho do salário, e as horas de lazer, que muitas vezes implicam gasto de dinheiro. $O$ corpo passa a ser visto muito mais como aquilo que se tem do que aquilo que se é (SANT'ANNA, 2001).

Nessa dinâmica, os produtos tornam-se bens simbólicos em constante mudança de valores, dada pelo consumo como um processo sociocultural. Para Villaça (2002), as apropriações dos produtos se dão de várias formas, uma vez que cada consumidor dota o objeto de um significado particular. Os bens simbólicos acabam delimitando fronteiras entre os grupos, criando e demarcando diferenças, auxiliando a demarcação de classes e a afirmação de gostos. O simbolismo desses bens contribui para a construção de modelos variados que atuarão como marcadores sociais. Produzem-se agora desejos na forma de signos e não de objetos materiais, portanto, pode-se dizer que o consumo é menos alguma coisa real e mais propriamente um signo, porque é o signo que se deseja (VILLAÇA; GÓES, 1998). Se, antes da modernidade, o ser e o parecer estavam unidos pela tradição, agora a união desses termos se estabelece pela vontade do indivíduo, que quer parecer o que não é, não sendo o que parece, mas 
podendo se tornar este ser. Tal jogo de aparências só é possível por meio das transformações corporais que se consolidam em artifícios para a reunificação do ser/parecer.

O corpo, neste contexto, também se torna um produto, já que uma das tendências da sociedade de consumo é atribuir ao indivíduo a responsabilidade pela plasticidade corpórea. $\mathrm{O}$ corpo 'natural' é muitas vezes considerado obsoleto: vive-se num mundo no qual o artificial e a aparência são mais importantes que este corpo. A cultura de consumo instiga a criação de necessidades e desejos, e possibilita um número maior de opções. $O$ indivíduo da sociedade de consumo é inserido num espectro global de fluxos, redes e imagens, uma produção incessante de serviços e desejos (VILLAÇA, 1998). Presencia-se um forte imaginário contemporâneo que busca no corpo, assim como em outros objetos, uma possível verdade sobre si mesmo; aquela que a sociedade parece não conseguir mais Ihe proporcionar, uma vez que a evolução desenfreada da tecnologia causa sentimentos de ameaça e incerteza ao homem contemporâneo. Assim, na falta de realizar-se em sua própria existência, procura realizar-se por meio de seu corpo, transformado segundo seus desejos e intenções.

A revolução tecnológica não alterou apenas os hábitos e maneiras dos indivíduos em relação ao seu modo de viver, de interagir com o mundo e com os outros ao seu redor, mas influenciou principalmente sua mudança física. A nova estética identitária é dirigida pela mutação. $O$ corpo passou a receber um infindável número de informações e uma extensa quantidade de substâncias para conseguir viver melhor. Tais transformações, independente da maior ou menor vinculação com a estética, contribuem para a alteração do corpo e promovem novo comportamento e nova vida.

\section{A valorização da imagem}

A multiplicação, num curto intervalo de tempo, de redes de computadores, transmissão por satélite, cabos de fibras ópticas e mecanismos eletrônicos de transferência de dados e informações em alta velocidade, desencadeou uma revolução na comunicação. A introdução de novas técnicas gerou uma dinâmica em que o potencial transformador das sociedades modernas se multiplicou numa velocidade muito maior do que a necessária para que as pessoas pudessem compreender ou refletir sobre seus impactos futuros. Essa revolução na comunicação permitiu o fortalecimento da publicidade e o consumismo, tornando-os a ideologia por excelência. Todo o legado cultural foi diluído num conjunto de fórmulas padronizadas, de extensão, duração e efeito calculados, para terem preço mínimo em função de uma ampliação máxima de seu consumo. De acordo com Jameson (1995), tudo na sociedade de consumo assumiu uma dimensão estética. Com a tecnologia, surgiu a fotografia, o cinema, a televisão, possibilitando a divulgação e a publicação de imagens. As câmeras se tornaram cada vez mais simples, pequenas e leves. Os filmes se tornaram falados e coloridos, enquanto as televisões se propagaram, via cabo, satélite e até mesmo on-line.

De fato, sabe-se que a visão é um dos mais atuantes canais sensoriais do homem, pois é ela quem abre caminho à apreensão de significações nas linguagens. A experiência de mundo de cada indivíduo realiza-se por meio dos sentidos. A primeira experiência por que passa uma criança em seu processo de aprendizagem ocorre através da consciência tátil. Além desse conhecimento 'manual', o reconhecimento inclui o olfato, a audição e o paladar, num intenso e fecundo contato com o meio ambiente. Estes sentidos são rapidamente intensificados e superados pelo plano icônico - a capacidade de ver, reconhecer e compreender, em termos visuais, as forças ambientais e emocionais. Praticamente, desde a primeira experiência de mundo, passa-se a organizar as necessidades e os prazeres, as preferências e os temores, com base naquilo que se vê. Dentre os cinco sentidos, o olhar foi privilegiado. Para o historiador Michel de Certeau (1994, p.48), "a sociedade contemporânea se caracteriza por um crescimento canceroso da visão, medindo a tudo por sua capacidade de se mostrar ou de ser visto e transformando a comunicação num percurso visual". Vive-se sempre com a sensação de que a realidade é menos interessante do que a imagem dela mesma (MESQUITA, 2004). O indivíduo se vê perdido numa dinâmica que oferece tudo, exceto uma solução para concretizar sua identidade, devido ao abarrotamento de imagens de vida que são oferecidas pelo consumo. Essa explosão de imagens, juntamente com o avanço tecnológico, coloca em crise a razão, fazendo do corpo a superfície privilegiada para a inscrição de sentidos, para o caminho do ser e do tornar-se, na busca da referida 
identidade.

De acordo com Magalhães (2006, p.80), “hoje, habita-se um mundo em que uma imagem vale por mil palavras", o que resulta numa situação na qual as imagens são mais importantes que os conteúdos. A supremacia do olhar e da visualidade prevalece sobre os outros sentidos. Embora seja indiscutível a importância da imagem como portadora de informações que produzem sentido, a sua valorização em detrimento à palavra, ao pensamento, à subjetividade, leva a um mundo de aparência e superficialidade, no qual o mais relevante reside naquilo que se vê e que se mostra. A velocidade da circulação das imagens provoca discussões sobre a crise da representação, da perda dos relatos, projetos e fundamentos, sendo valorizado novamente o corpo e o modo de se apresentar na busca de uma identidade social. Num cenário aparentemente caótico, de um mundo fragmentado, caleidoscópico, habitado por simulacros e imagens, atenta-se para o que ocorre na área da percepção visual: um efeito dominante que parece uma avalanche de imagens, que embaralham e ofuscam os olhos, tornando os indivíduos, antes vítimas, que senhores do próprio olhar (SEVCENKO, 2001). Comparando os seres humanos ao comportamento de simples amebas, Sant'Anna (2001) afirma que é como se todos agissem sempre por reflexos e jamais pela reflexão, pois mesmo havendo informação em grande quantidade, não há tempo suficiente para assimilá-la, e esta informação acaba sendo simplesmente acumulada. Os sinais não são decodificados, portanto, não se tornam informações. No ritmo em que as mudanças ocorrem provavelmente nunca se terá tempo suficiente para parar e refletir, tornando-se cada vez menos importante a pergunta sobre a causa e efeito de todos os processos, já que, definitivamente, essa inserção numa rede veloz provoca um curto-circuito nos sentidos.

Segundo Sevcenko (2001), foi a partir da introdução da imprensa mecanizada que se consolidou esta cultura centrada na visão que enfatiza valores abstratos, racionais, hierárquicos e cumulativos, além do anseio pelo futuro.

O advento das técnicas eletro- eletrônicas reformulou esse contexto ao atribuir um novo papel ao olhar, não mais estático como aquele condicionado pela imprensa e pela perspectiva linear do Renascimento, mas um olhar agora onipotente e onipresente, dinâmico, versátil, intrusivo, capaz de se desprender dos limites do tempo e do espaço. (SEVCENKO, 2001, p. 80)

Habita-se um mundo onde há um bombardeio maciço e aleatório de informações que não se constituem como um todo. A realidade é fragmentada em retalhos, composta por vivências parciais. Não há uma crença na totalidade, visto que esta é plural. O ambiente contemporâneo é povoado pela cibernética, pela robótica, pela medicina nuclear, uma verdadeira 'Revolução da Microeletrônica', como denomina Sevcenko (2001, p. 16). Esse mundo pode ser traduzido por imagens e signos, e a velocidade é sua característica mais marcante.

O surto vertiginoso das transformações tecnológicas não apenas abole a percepção do tempo: ele também obscurece as referências do espaço. Foi esse o efeito que levou os técnicos a formular o conceito de globalização, implicando que, pela densa conectividade de toda a rede de comunicações e informações envolvendo o conjunto do planeta, tudo se tornou uma coisa só. (SEVCENKO, 2001, p. 20)

Este mundo abarrotado de imagens aponta um corpo ideal, desejado por todos, padronizado, bonito, leve e jovem, totalmente construído e perfeito, sem rugas nem doenças, com próteses e brilhos, um corpo virtual, retocado e a cada dia mais plastificado (MAGALHÃES, 2006). Na busca de adequar o corpo ao espaço que Ihe foi destinado, aquele que é considerado como um bem de consumo, que pode ser comercializado; bem como adequar aos padrões de perfeição estabelecidos que se traduzem por ágil, jovem, leve e saudável, criou-se certa fobia, e todos os recursos possíveis são utilizados para conquistar este corpo. No entanto, como ele está totalmente distante do natural, é preciso estar dentro de outro corpo, mesmo que, para isso, seja necessário retalhá-lo e incorporar a ele outros elementos artificiais que permitam que este se mantenha belo e eternamente jovem. Neste 
mundo, em que a felicidade deixa de ser uma virtude para se transformar em objeto de consumo, a saúde toma o mesmo rumo e o indivíduo começa a buscar por um corpo capaz de se movimentar por muitos espaços e ultrapassar todas as fronteiras.

O excesso de informação coloca em crise a maneira de se identificar e ser identificado pelo outro, porque ao abandonar um antigo sistema rígido de regras, a moda passa a ser "uma estratégia corporal na busca de mais expressão, propiciando movimentos de simulação e dissimulação, aumentando o poder do corpo de afetar e ser afetado" (VILLAÇA, 2002, p. 93). Nesse meio, o mecanismo vigente na sociedade age sobre o corpo, instigando o desejo de parecer-se com o outro, aquele que é um reflexo de tudo aquilo com que se é violentamente bombardeado: algo como um produto qualquer, numa urgência para o presente que se esgota no aparecer (VILLAÇA, 2002). Um vasto campo de imagem, considerado padrão, é oferecido como se fosse a única referência para se apresentar o corpo, o vestuário e a beleza.

A relação temporal está sendo alterada pela revolução informacional, ocasionando mudanças na percepção sensorial do ser humano. Há uma sensação de desnorteamento, de vazio, de falta de referências (MESQUITA, 2004). Tudo está em estado permanente de construção e desconstrução, sendo efêmero, passageiro e transitório. Para Baudrillard (1990, p. 29), "esse processo passa pela questão da estetização da vida cotidiana e pela transformação da realidade em imagens", caracterizadas, segundo Jameson (1995), pela perda de sentido de história e fragmentação do tempo numa série de presentes perpétuos, em que se verifica a experiência de intensidades multifrênicas, com o apagamento da fronteira entre o real e a imagem numa cultura sem profundidade, marcada pela sobrecarga sensorial. Nesse sentido, a estetização da vida refere-se ao fluxo veloz dos signos e das imagens que saturam o cotidiano na sociedade contemporânea. A velocidade das transformações contemporâneas faz com que cada vez mais o espaço não seja visto como algo exterior ao indivíduo, passando a elemento constitutivo de sua estruturação (VILLAÇA; GÓES, 1998).

\section{A velocidade e o novo padrão estético}

O mundo está mudando, mas a novidade não consiste na mudança em si, afinal, isto sempre aconteceu. O diferencial está na grande velocidade com que as mudanças ocorrem. A partir do momento em que tal velocidade é conquistada, todo peso material tende a ser percebido como um mero obstáculo a ser ultrapassado, o que torna o peso do corpo, um deles. Procura-se evitar que ele seja um impedimento para poder entrar em todos os lugares, passar por todos os tempos, navegar em meio a diferentes culturas (SANT'ANNA, 2001). O indivíduo vê na velocidade o signo do dinamismo e na transparência, na leveza do corpo, a imagem de um mundo que oferece a possibilidade de passar por tudo e todos sem nunca ser detido.

\footnotetext{
Uma das tendências da contemporaneidade é o modo como olhamos todas as coisas muito superficial e incompletamente e de maneira alienada. Esse modo 'horizontalizado' repete-se sempre com coisas e lugares, e isso se deve basicamente a um fator recorrente da vida moderna, a velocidade. A velocidade reduz distâncias, altera o conceito de tempo e a dimensão dos espaços abolindo também a perspectiva; da tridimensionalidade para a bidimensionalidade, sentido plano; imagens chapadas, sem profundidade. (CASTILHO, 2004, p. 52)
}

Essa superficialidade, que muitas vezes provoca uma visão distorcida da realidade, também pode ser identificada quando se trata do corpo. O ser humano apresenta uma relação instigante com seu próprio corpo e com a imagem que por ele se constrói. Segundo Souza (2008, p. 337), embora a estrutura corpórea apresente três dimensões, os indivíduos possuem uma consciência abstrata dessa tridimensionalidade, pois poucos percebem com exatidão o próprio corpo. Em geral, a imagem corporal que o sujeito tem de si, é uma figura plana, sem profundidade. A bidimensionalidade exclui a condição do corpo de se apresentar como tridimensional, aspecto primordial para o corpo vestido, para a produção no espaço das ações e experiências sensoriais da mobilidade, da massa que se torna 
visualidade processando a aparência. A dimensão da profundidade, que dá à materialidade o sentido de ser algo palpável, corpóreo, perde-se no universo de imagens planas, das representações imagéticas superficiais. Mesquita (2004) afirma que o indivíduo acaba esquecendo-se de sentir seu corpo real, que possui vivacidade e sensibilidade, em virtude de inúmeras variáveis como: a supervalorização da aparência, a falta de tempo e a busca à eterna juventude. Para a autora, isto acarreta uma baixa propriocepção, que se trata da capacidade de perceber o próprio corpo.

A velocidade, que tanto afeta a maneira como se percebe e se sente o mundo e as coisas ao redor, teve início com as mudanças tecnológicas. A Revolução Industrial trouxe a aceleração do tempo da produção, o que proporcionou mudanças rápidas na reconfiguração dos espaços sociais e políticos (VILLAÇA; GÓES, 1998). Assim como as inovações tecnológicas alteraram as estruturas: econômica, social e política, mudaram ao mesmo tempo a condição de vida das pessoas e as suas rotinas. Numa sociedade altamente mecanizada, homens e mulheres deveriam se adaptar ao ritmo e à aceleração das máquinas, e não o contrário (SEVCENKO, 2001). Não apenas a percepção do tempo foi afetada pela velocidade, mas o organismo humano também passou a arcar com as consequências dessa aceleração. De acordo com Sant'Anna (2001, p.44), “o organismo humano devia trabalhar cada vez mais rápido, queimar com facilidades os alimentos e transformá-los em energia produtiva", assemelhando-se ao motor de combustão, intensamente presente no cotidiano das pessoas daquele período, a maioria da classe trabalhadora.

A velocidade não estaria associada apenas ao processo de produção nas indústrias, mas ela começava a se inserir nas cidades, formulando um novo padrão estético. Os automóveis aos poucos tomaram o lugar dos transportes de tração animal, e as formas aerodinâmicas ganharam destaque ao demonstrar que dominavam o movimento e a aceleração (SANT'ANNA, 2001). A economia de formas sobre um mínimo de volume transformou-se na estética dominante tanto nos automóveis, quanto nos eletrodomésticos e móveis. Contudo, muitas das formas com linhas aerodinâmicas foram guiadas por preocupações puramente estilísticas, a exemplo de aparelhos domésticos como aspiradores e refrigeradores, nos quais não se detectava uma necessidade real que justificasse o comportamento aerodinâmico (FIELL; FIELL, 2001). Entretanto, essa tendência influenciou também a aparência dos moradores das grandes cidades, conforme afirma Sant'Anna (2001, p.43): “corpos longilíneos, capazes de mostrar agilidade e flexibilidade, especialmente no trabalho, pareciam fornecer um estado de decência e elegância incontestável". Com esta espécie de generalização da aversão a tudo o que impediria a emergência das formas e atitudes aerodinâmicas, instaurou-se a intolerância ao peso e a toda espera.

Paralelamente, a moda, sendo um elemento substancial da modernidade, instrumento para detectar o 'espírito do tempo', segundo caracteriza Flugel (1966), passou a ser menos uma sucessão de volumes e muito mais um jogo de linhas sobre um espaço plano. Seguindo a estética do aerodinamismo, novos padrões comportamentais apresentaram-se, desafiando os valores morais da época, como a depilação de pernas e axilas, e o uso de cremes antirrugas. $O$ investimento no aerodinamismo dos costumes e das aparências uniu-se harmoniosamente à valorização do automatismo e da juventude. Isso incentivou o surgimento de padrões encontrados até hoje na sociedade, como a praticidade dos cabelos lisos, fáceis e rápidos de pentear, e a busca por rostos isentos de marcas do tempo, refletindo uma beleza sintética, que expressa juventude e agilidade. Para Sant'Anna (2001, p.44), "esses modismos acentuam a aversão aos relevos epidérmicos e a toda superfície que não seja um convite ao toque efêmero e ao passeio rápido do olhar".

Pode se afirmar que o 'passeio rápido do olhar' está intimamente ligado ao padrão estético do corpo magro, uma vez que ele "evoca uma economia de tempo para quem o aprecia: olha-se mais rápido um magro do que um gordo" (SANT'ANNA, 2001, p.23). Nos dias atuais, em que a aceleração se faz tão presente, a plástica do corpo acaba sendo obsessivamente remodelada. Embora durante séculos o corpo tivesse sido considerado o espelho da alma, agora ele é chamado a ocupar o seu lugar, mas sob a condição de se converter completamente em boa forma. A gordura, que em outros períodos estava associada à saúde, riqueza e poder, passa a ser vista como algo que atrapalha, incomoda, ocupa espaço. Os corpos gordos e redondos, que até o início do século XX exibiam o charme de seu peso com orgulho, significando saúde e prestígio social, hoje não são mais propícios nos apartamentos minúsculos, 
carros minúsculos, cadeiras minúsculas. Quem não couber, acaba se considerando descartado, garante Magalhães (2006).

A redução do espaço se expressa principalmente nas máquinas e nos objetos de uso pessoal. Centenas de artefatos eletrônicos tendem a ter a extensão de suas distâncias reduzidas, o que facilita a tarefa de portá-los. A miniaturização dos objetos e dos espaços torna-se, juntamente com a aceleração, tendência que influencia o modo de vida da sociedade contemporânea. Formas e volumes são cada vez mais controlados, construídos e idealizados: uma imagem da perfeição. A velocidade substitui a duração pelo instantâneo, e neste percurso, a materialidade dos corpos passa por uma desmaterialização.

Com a velocidade intensamente presente na contemporaneidade, os indivíduos tornam-se devoradores de conceitos prontos, pré-moldados, pré-fabricados. Para não se perder muito tempo refletindo, opta-se por comprar uma imagem pronta e aplicá-la à vida. Desse modo, tornam-se todos, prisioneiros de um olhar sempre atrelado aos modelos impostos. Embora a moda possibilite a cada um, a constituição de sua subjetividade, na busca pela diferenciação, muitas vezes os indivíduos acabam assemelhando-se uns aos outros, por se referenciarem na mesma diversidade de padrões difundidos pelo mundo. Nesse aspecto, a moda acaba por cair em um sistema contraditório: ao atuar como um mecanismo de pluralização das diferenças, inserindo a novidade, ela diferencia os sujeitos ao mesmo tempo em que os torna mais semelhantes. Para Lipovetsky (1989), a ambigüidade da moda está no fato de que ao mesmo tempo em que ela possibilita a individualização por meio de instrumentos diferenciados, paralelamente também propõe a padronização do vestir. No mesmo instante em que se produz a diferença, dando suporte ao indivíduo para estabelecer sua diferenciação, ela é anulada, servindo como padronização do vestuário, novamente em um processo horizontalizante, que obedece a normas pré-estabelecidas.

\section{Considerações Finais}

O corpo é um dos 'objetos' que mais assume valores simbólicos relevantes no cenário contemporâneo. Por meio dele, cada indivíduo constitui-se como sujeito, construindo sua imagem como forma de interação com o mundo e com os outros ao redor. A presença do vestuário faz-se necessária como intermediadora destas relações. Uma vez que cada sociedade cria seus valores, a roupa não se limita à função de proteção, pudor ou adereço, mas constitui-se um elemento de diferenciação. Portanto, a moda, assim como o corpo, é considerada uma forma de linguagem. A moda evidencia as mudanças de cada época, porque as necessidades de cada período histórico são concretizadas através dos corpos dos indivíduos, pelo vestuário, que sofre modificações, sintonizado aos desejos de cada momento da história humana.

$\mathrm{Na}$ contemporaneidade, mais do que em contextos anteriores, os corpos são redesenhados com as marcas desse período, devido às inúmeras possibilidades de serem vestidos, tecnologizados ou submetidos a sacrifícios em função da aparência. As evoluções tecnológicas determinam uma reformulação comportamental, afetando principalmente o quadro de valores da sociedade. O vestuário, que antes caracterizava o sujeito segundo as regras sociais de hierarquia, gênero ou profissão, deixa de desempenhar tal função ao romper-se a relação entre o ser e o parecer. Com o surgimento das cidades, consolidam-se as condições para que a aparência esteja cada vez mais dissociada do ser.

Em meio a inúmeras mudanças, de uma sociedade industrial para uma sociedade capitalista, as pessoas passam a ser aquilo que consomem, fundando uma cultura baseada na relação do parecer. As relações tornam-se superficiais, sem profundidade, e o corpo, assim como qualquer outro objeto, transforma-se em mercadoria, exposto em diversas mídias, apresentando-se como um modelo ideal, jovem e plastificado. A velocidade da circulação das imagens no contemporâneo provoca discussões sobre a crise da representação e a perda dos fundamentos. Instaura-se uma sensação de desnorteamento e de vazio, que colocam em questão a busca pela identidade: apesar da abundância de informação, a falta de tempo não permite que seja assimilada.

A velocidade gera novos padrões estéticos e comportamentais. O corpo leve, magro, bidimensionalizado, é imposto pela aerodinâmica, pela economia de formas, pela miniaturização 
Brandes, Aline Zandonadi; Souza, Patricia de Mello

dos objetos e espaços. Em tal contexto, com formas prontas oferecidas a todo o momento, ritmo acelerado e ausência de tempo para questionamentos e reflexões, a moda, que deveria ser um fator de diferenciação, um mecanismo utilizado pelo sujeito como meio de exteriorização de sua subjetividade, cai num sistema contraditório, obedecendo a regras impostas.

\section{Referências}

AVELAR, Suzana. Moda: globalização e novas tecnologias. São Paulo: Estação das Letras e Cores, 2009.

BAUDRILLARD, Jean. A transparência do mal: ensaio sobre os fenômenos extremos. Trad. Estela dos Santos Abreu. Campinas: Papirus, 1990.

CASTILHO, Kathia. Do corpo presente à ausência do corpo: moda e marketing. Dissertação [Tese de Doutorado em Comunicação e Semiótica] - PUC, São Paulo, 2004.

CASTILHO, Kathia ; MARTINS, Marcelo M. Discursos da moda: semiótica, design e corpo. São Paulo: Editora Anhembi Morumbi, 2005.

CASTILHO, Kathia. Interrelações da mídia, do design do corpo e do design da moda. In: GARCIA, Wilton (Org). Corpo e Subjetividade - estudos contemporâneos. São Paulo: Factasch Editora, 2006. p. 86-96.

CERTEAU, Michel. A invenção do cotidiano, artes do fazer. Petrópolis: Vozes, 1994.

CRANE, Diana. A moda e seu papel social: classe, gênero e identidade das roupas. São Paulo: Senac, 2006.

FIELL, Charlotte e FIELL, Peter. Design Industrial A-Z. Italy: Taschen, 2001.

FLÜGEL, John Carl. A psicologia das roupas. São Paulo: Mestre Jou, 1966.

JAMESON, Fredric. As marcas do visível. Rio de Janeiro, Graal, 1995.

LE BRETON, David. A sociologia do corpo. Petrópolis: Vozes, 2006.

A síndrome de Frankenstein. In: SANT' ANNA. Denise B. (Org). Políticas do corpo. São Paulo: Estação Liberdade, 1995. p.49-67.

LIPOVETSKY, Gilles. O império do efêmero: a moda e seu destino nas sociedades modernas. São Paulo: Cia das Letras, 1989.

MAGALHÃES, Fernanda. Corpo re-construção ação, ritual, performance. In: GARCIA, Wilton (Org). Corpo e Subjetividade - estudos contemporâneos. São Paulo: Factasch Editora, 2006. p.76-85.

MCLUHAN, M. Os meios de comunicação como extensões do homem. São Paulo: Cultrix, 1964.

MESQUITA, Cristiane. Moda contemporânea: quatro o cinco conexões possíveis. São Paulo: Editora Anhembi Morumbi, 2004.

OLIVEIRA, Ana Claudia. Visualidade processual da aparência. In: OLIVEIRA, Ana Claudia; CASTILHO, Kathia (Org.). Corpo e Moda: por uma compreensão do contemporâneo. Barueri, SP: Estação das Letras e Cores Editora, 2008. p.94-104.

SANT'ANNA, Denise B. Corpos de passagem: ensaios sobre a subjetividade contemporânea. São Paulo: Estação Liberdade, 2001. 
SEVCENKO, Nicolau. A corrida para o século XXI: no loop da montanha russa. São Paulo: Cia das Letras, 2001.

SOUZA, Patrícia de Mello. A moulage, a inovação formal e a nova arquitetura do corpo. In PIRES, Dorotéia Baduy (Org.). Design de Moda: olhares diversos. São Paulo: Estação das Letras e Cores, 2008. p.337-346.

VILLAÇA, Nízia e GÓES, Fred. Em Nome do Corpo. Rio de Janeiro: Rocco, 1998.

VILLAÇA, Nízia. Alta, média e baixa costura: moda e semiologia cultural. In: CASTILHO, Kathia; GALVÃO, Diana (Org.). A moda do corpo e o corpo da moda. São Paulo: Esfera, 2002. p.91-104.

Editora, 2007. . A edição do corpo: tecnociência, artes e moda. Barueri, SP: Estação das Letras

WILSON, Elizabeth. Enfeitada de sonhos. Lisboa: Edições 70, 1989. 